\title{
Ovariectomy of Adult Rats Leads to Increased Expression of Astrocytic Basic Fibroblast Growth Factor in the Ventral Tegmental Area and in Dopaminergic Projection Regions of the Entorhinal and Prefrontal Cortex
}

\author{
Cecilia Flores, Natalina Salmaso, Sean Cain, Demetra Rodaros, and Jane Stewart \\ Center for Studies in Behavioral Neurobiology, Department of Psychology, Concordia University, Montréal, Québec, \\ Canada H3G 1 M8
}

Changes in astrocytic function may underlie the neurochemical and morphological alterations in limbic and cortical areas after estrogen loss in adult females. We assessed whether increased expression of basic fibroblast growth factor (bFGF), an astrocytic response involved in injury-induced neuronal plasticity, occurs after ovariectomy. We examined bFGF immunoreactivity (IR) in ovariectomized rats with oil or estradiol benzoate $(5 \mu \mathrm{g}$ every $4 \mathrm{~d}$; Experiment 1) and in ovariectomized and intact animals (Experiment 2). In the ventral tegmental area (VTA), bFGF-IR and glial fibrillary acidic protein (GFAP)-IR were greater in ovariectomized animals than in animals with estrogen replacement. bFGF-IR in the VTA was greater in ovariectomized than in intact females. In the dorsal raphe, no differences between groups were found in GFAP-IR or bFGF-IR. In mesolimbic dopaminergic target areas within entorhinal cortex (Ent), prefrontal cortex, and nucleus accumbens, bFGF-IR was higher

Estrogens have widespread influence on affective and cognitive functioning in adult females. Estrogens and their loss have been implicated in mood changes (Fink et al., 1996) and memory (Sherwin, 1997) as well as in mental disorders (Gregoire et al., 1996; Henderson, 1997; Lindamer et al., 1999). Ovariectomy has been associated with morphological and neurochemical changes in cortex and hippocampus. In rats, ovariectomy leads to rapid decreases in dendritic spine density of hippocampal CA1 pyramidal cells that are prevented by estradiol (E2) (Gould et al., 1990). These effects appear to be mediated indirectly via changes in glutamatergic tone (Woolley and McEwen, 1994) through E2 actions on brain-derived neurotrophic factor and GABAergic activity (Murphy et al., 1998a,b). In contrast, increased dendritic branching and spine density of parietal cortex pyramidal cells are observed in long-term ovariectomized rats (Stewart and Kolb, 1994), effects similar to those seen after early injury to adjacent cortical regions and to noradrenergic inputs (Kolb et al., 1997). These findings suggest that changes in cell morphology induced by ovariectomy could result from the loss of estrogenic actions on

\footnotetext{
Received June 3, 1999; revised July 16, 1999; accepted July 20, 1999.

This work was supported by grants to J.S. from the Natural Science and Engineering Research Council of Canada and Fonds pour la Formation de Chercheurs et l'Aide à la Recherche (FCAR, Québec). C.F. was supported by a graduate fellowship from Concordia University.

Correspondence should be addressed to Dr. Jane Stewart, Center for Studies in Behavioral Neurobiology, Department of Psychology, Concordia University, 1455 de Maisonneuve Boulevard, Montréal, Québec, Canada H3G 1M8.

Copyright (C) 1999 Society for Neuroscience $0270-6474 / 99 / 198665-09 \$ 05.00 / 0$
}

in Ent of ovariectomized animals 4 weeks after surgery in both experiments, but no differences were seen in nucleus accumbens or in an occipital cortical, control, area in either study. In Experiment 2, small increases in bFGF-IR were seen in the prefrontal cortex after ovariectomy. In the VTA and Ent, changes in bFGF-IR developed gradually, peaking at 4 weeks and waning at 40 weeks. Furthermore, increased dendritic arbor of Ent layer II/III pyramidal cells was found in ovariectomized females with the use of a modified Golgi-Cox staining procedure. These findings suggest that, within specific regions, ovariectomy induces astrocytic responses similar to those observed after injury that may affect neuronal chemistry and morphology.

Key words: estrogen; astrocytes; bFGF; ventral tegmental area; entorhinal cortex; prefrontal cortex; dendritic arbor; Golgi; GFAP

cells that innervate the affected cells, causing compensatory reactions in the target cells to changes in previous patterns of input. In fact, estrogen loss results in reduced cholinergic activity in cortex and hippocampus (Luine, 1985; Singh et al., 1994), and such effects probably are mediated by alterations in the effects of neurotrophins on cholinergic cells of the basal forebrain (ToranAllerand et al., 1992; Sohrabji et al., 1995; McMillan et al., 1996; Gibbs, 1998).

Ovariectomy induces changes in other systems that have widespread influence on the cortex, such as the midbrain dopaminergic and serotonergic systems. In adult monkeys, long-term ovariectomy decreases dorsal raphe tryptophan hydroxylase but increases 5-HT1A receptor and transporter mRNA expression (Pecins-Thompson et al., 1996, 1998; Pecins-Thompson and Bethea, 1999) and substantially reduces tyrosine hydroxylaseimmunoreactive fiber density in the cortex (Kritzer and Kohama, 1998). In rats, ovariectomy decreases 5-HT2A receptor mRNA expression and binding (Fink and Sumner, 1996; Fink et al., 1996) and dopamine receptor binding (Bossé and Di Paolo, 1996). Furthermore, the behavioral and neurochemical effects of drugs that act directly on dopaminergic neurons are decreased after ovariectomy (Camp et al., 1986; Robinson, 1988; Becker, 1990; Castner et al., 1993; Forgie and Stewart, 1993, 1994; Stewart and Rodaros, 1999).

Recent evidence shows that estrogens are neuroprotective (Dluzen et al., 1996; Dluzen, 1997; Green et al., 1997), suggesting that their loss might induce responses seen after minor injury. 
Estrogen loss and replacement affect astrocytic activity (Luquin et al., 1993), and the effects of estrogens on neuronal function might be mediated in part via their actions on astrocytes (GarcíaSegura et al., 1994, 1996). Interestingly, astrocytic expression of basic fibroblast growth factor (bFGF) is increased in midbrain dopamine cell body regions after injury to dopaminergic cells (Chadi et al., 1994) and after repeated injections of psychostimulant drugs (Flores et al., 1998). Thus, because of the sensitivity of the monoamine systems to estrogen loss and replacement, we hypothesized that, after ovariectomy, astrocytes in cell body and/or target regions of these systems might show changes in bFGF expression similar to those seen in response to stress, drugs, or minor injury. In addition, we speculate that these changes may be related to the morphological changes in cortical regions that are seen after estrogen loss.

\section{MATERIALS AND METHODS}

\section{Subjects}

Female Wistar rats (Charles River, St. Constant, Québec) 80-90 d of age at the time of surgery served as subjects in Experiments 1, 2, and 3. All animals were maintained in a temperature- and humidity-controlled environment under a $12 \mathrm{hr}$ light/dark cycle with free access to food and water.

\section{Hormones and antibodies}

Estradiol benzoate (EB; Sigma, St. Louis, MO), was dissolved in peanut oil and injected subcutaneously at a dose of $5 \mu \mathrm{g} / 0.1 \mathrm{ml}$ per animal or, as in Experiment 4, $10 \mu \mathrm{g} / 0.1 \mathrm{ml}$ per animal. bFGF immunoreactivity was detected by using a mouse monoclonal antibody (Upstate Technology, Lake Placid, NY) that recognizes the biologically active isoform of bFGF (Matsuzaki et al., 1989). The antibody was used at a concentration of 1:500. A mouse monoclonal antibody (Sigma), at a concentration of 1:500, was used to identify glial fibrillary acidic protein (GFAP) immunoreactivity; a rabbit polyclonal antibody (Eugene Tech, Ramsay, NJ), at a concentration of 1:2000, was used for tyrosine hydroxylase $(\mathrm{TH})$ immunolabeling.

\section{Immunohistochemistry}

Animals were anesthetized deeply with sodium pentobarbital $(120 \mathrm{mg} /$ $\mathrm{kg}$ ) and perfused transcardially with $200 \mathrm{ml}$ of cold PBS, followed by 100 $\mathrm{ml}$ of a cold solution of $4 \%$ paraformaldehyde $(\mathrm{w} / \mathrm{v})$ and $15 \%$ picric acid $(\mathrm{v} / \mathrm{v})$ in phosphate buffer (PB; $\mathrm{pH}$ 6.9). Brains were removed and stored overnight in the fixative solution at $4^{\circ} \mathrm{C}$. Coronal $50 \mu \mathrm{m}$ sections were cut by vibratome and stored overnight in $\mathrm{PB}$ at $4^{\circ} \mathrm{C}$. In Experiment 1, adjacent brains sections were processed for GFAP or bFGF immunohistochemistry (in Experiment 2, only for bFGF) by using the ABC method (Hsu et al., 1981). Free-floating sections were incubated for $24 \mathrm{hr}$ at $4^{\circ} \mathrm{C}$ with the anti-bFGF or anti-GFAP antibody diluted 1:500 with $0.3 \%$ Triton X-100 (Sigma) in PB and $1 \%$ normal horse serum (Vector, Burlingame, CA). Then the sections were rinsed (three times for $5 \mathrm{~min}$ ) in cold $\mathrm{PB}$ and incubated for $1 \mathrm{hr}$ at room temperature in a solution of rat adsorbed biotinylated anti-mouse antibody (Vector) diluted 1:200 with $\mathrm{PB}$ and $1 \%$ normal horse serum. After washings (three times for 5 min) in cold $\mathrm{PB}$, the sections were incubated in an avidin-horseradish peroxidase complex (Vectastain Elite ABC Kit, Vector) for $30 \mathrm{~min}$ at room temperature and rinsed again (three times for $5 \mathrm{~min}$ ) in cold $\mathrm{PB}$. Next the sections were incubated for $10 \mathrm{~min}$ at room temperature, and, under constant agitation, in a solution of $0.05 \% 3,3^{\prime}$-diaminobenzidine (Sigma) in PB. Then, without washing, the sections were transferred to a 3, $3^{\prime}$-diaminobenzidine/ $\mathrm{PB}$ solution, $\mathrm{pH} 7.8$, with $0.01 \% \mathrm{H}_{2} \mathrm{O}_{2}$ to catalyze the reaction and with $8 \% \mathrm{NiCl}_{2}$ to darken the reaction product. This incubation was terminated $8 \mathrm{~min}$ (bFGF-treated sections) or $3 \mathrm{~min}$ (GFAP-treated sections) later by washing the sections (three times for 10 min) with cold PB.

Double labeling for bFGF-GFAP and for bFGF-TH was obtained by processing the sections, first, for bFGF immunoreactivity and then for either GFAP or TH immunoreactivity, using the ABC method. For TH immunoreactivity the sections were preincubated in $0.3 \%$ Triton X-100 $\mathrm{PB}$ and $1 \%$ normal goat serum for $1 \mathrm{hr}$ at room temperature. For both GFAP and $\mathrm{TH}$ immunoreactivity no $\mathrm{NiCl}_{2}$ was added to the $3,3^{\prime}$ -
diaminobenzidine-PB- $\mathrm{H}_{2} \mathrm{O}_{2}$ solution to obtain a lighter reaction product.

Sections were mounted on gelatin-coated slides, dried for at least $1 \mathrm{~d}$, hydrated in distilled water $(1 \mathrm{~min})$, and gradually dehydrated in 70,90 , and $100 \%$ ethanol. Slides then were cleared in Hemo-De and coverslipped with Permount. To reveal anatomical landmarks, we lightly counterstained midbrain sections for Nissl substance by using $0.1 \%$ cresyl violet. This latter step was not done in double-labeled tissue.

\section{Image analysis}

Immunostained sections were observed under a Leica microscope (Leitz DMRB, Wetzlar, Germany). Quantitative analysis was performed via an image analysis system (National Institutes of Health Image 1.6) on digitized images of sampling areas of the dorsal raphe nucleus (DR), ventral tegmental area (VTA), nucleus accumbens (NAcc) shell and core, entorhinal cortex (Ent) layer II, medial prefrontal cortex (PFC) layer II of the supragenual cingulate cortex area 2, and occipital cortex area 2 mediolateral (Oc2) layers V and VI. Boundaries of cortical and subcortical structures were defined by using as a guide Zilles (1985) and Paxinos and Watson (1997), respectively. Sampling areas of the DR were taken from sections corresponding to plates 47, 49, and 51; of the VTA, Ent, and Oc2 from sections corresponding to plates 38 and 39; of the NAcc from sections corresponding to plates 11, 12, and 13; and of the PFC from sections corresponding to plates 14 and 15 (Paxinos and Watson, 1997). Images for each structure (labeled with either bFGF or GFAP) were taken from three sections from each brain; they were digitized and assigned code names.

GFAP-immunoreactive surface density analysis. We performed a quantitative evaluation of the surface density of GFAP-immunoreactive cell bodies and cell processes according to the point-counting method of Weibel (1979), using a stereological grid. This method provides an estimate of the morphological changes in astrocytes (Luquin et al., 1993). For each image the number of points at which GFAP-immunoreactive cell bodies and cell processes crossed the test grid lines was assessed by an individual that was blind to the code designation. GFAPimmunoreactive surface density then was calculated by using the following formula: Surface Density $=2 I / L$, where $I$ is the number of points at which the immunoreactive profiles cross the test grid lines and $L$ is the total length of the test grid line (length of each test grid line $\times$ number of lines) in the tissue. The mean GFAP-immunoreactive surface density from the three sections for each structure in each animal was calculated. These values then were used to calculate group means \pm SEM per each brain region that was analyzed. The number of GFAP-positive cells in each of the digitized images also was counted to check for changes in the number of astrocytes expressing GFAP. From the work of others, however, it was not expected that hormone manipulations would result in changes in astrocytic number (Luquin et al., 1993).

bFGF immunoreactivity analysis. The number of bFGF-positive cells in each of the digitized images was counted by an individual that was blind to the code assignment. The mean cell counts from the three sections of each structure for each animal were calculated. Then these values were used to calculate group means \pm SEM per each area that was analyzed.

\section{Golgi}

For the study of dendritic branching the animals were given an overdose of pentobarbital and perfused transcardially with $0.9 \%$ saline at 4 weeks after ovariectomy. The brains were removed and immersed whole in 20 $\mathrm{ml}$ of a Golgi-Cox solution and left in the dark for $14 \mathrm{~d}$. Then the brains were placed in a $30 \%$ sucrose solution for $2 \mathrm{~d}$, cut on a vibratome at 200 $\mu \mathrm{m}$ (Gibb and Kolb, 1998), and developed by using a procedure described previously (Kolb and McLimans, 1986). Layer II/III pyramidal cells in the Ent were traced by using a camera lucida drawing tube magnified at $250 \times$. To be included in the data analysis, the dendritic trees of pyramidal cells had to fulfill the following criteria: (1) a cell had to be well impregnated and not obscured by blood vessels, astrocytes, or heavy clusters of dendrites from other cells; and (2) the apical and basilar arborization had to appear to be mainly intact and visible in the place of section. The branch segments and branch order were determined from the camera lucida drawings by using the procedure of Coleman and Riesen (1968). Branch order was determined for the apical dendrites such that branches originating from the primary apical dendrite were first order, after one bifurcation second order, and so on. For basilar dendrites, those originating at the cell body were first order, and so on. Ten cells were drawn per animal per area. Dendritic length was analyzed by using the concentric ring method of Sholl (1956). The number of inter- 
sections of dendrites with a series of concentric spheres at $20 \mu \mathrm{m}$ intervals from the center of the cell body was counted for each cell.

For each cell, spine density was measured from one apical dendritic branch in the terminal tuft, from an oblique branch running off the main apical dendritic shaft approximately half-way up the shaft, and from a secondary branch proximal to the cell body for one basilar branch, after the procedure of Woolley et al. (1990).

Brains from experimental and control subjects were always processed in parallel from perfusion to image analysis. In addition, special caution was taken to treat brains from each experimental condition in exactly the same manner: same fixative, time of post-fixation, washes, exposure to antibodies and chromogen, temperature, and dehydration.

\section{Design and procedures}

Experiment 1A: Expression of GFAP immunoreactivity. This experiment was conducted to determine the effect of ovariectomy and estrogen replacement on astrocytic morphology as reflected by changes in GFAPimmunoreactive surface density in serotonergic and dopaminergic somatodendritic regions. To this end, adult female rats were ovariectomized under methoxyflurane (Metofane) anesthesia by bilateral dorsal incisions. Animals then were assigned randomly to receive $5 \mu \mathrm{g}$ of EB (EB group) or $0.1 \mathrm{ml}$ of peanut oil (OIL group) every $4 \mathrm{~d}$ for 4 weeks. This replacement regimen is similar to that used by Forgie and Stewart (1993) and has been found to potentiate the locomotor-stimulating effects of amphetamine in ovariectomized animals. The animals were housed individually in standard stainless steel hanging cages throughout the entire study. At $24 \mathrm{hr}$ after the last EB or oil injection the animals were killed, and their brains were processed for GFAP immunoreactivity. Levels of GFAP-immunoreactive surface density and the number of immunoreactive cells were assessed in the DR and VTA.

Experiment 1B: Expression of bFGF immunoreactivity. bFGF immunoreactivity in the DR and VTA was studied in alternate sections from the brains of animals described in Experiment 1A. In addition, we measured bFGF immunoreactivity in projection regions of mesolimbic DA neurons: the NAcc shell, NAcc core, and layer II of the Ent and of the PFC (Fallon and Moore, 1978; Fallon and Loughlin, 1987; Akil and Lewis, 1993, 1994). For comparison, we measured bFGF immunoreactivity in layers $\mathrm{V}$ and VI of Oc2.

Experiment 2: Time course of changes in the expression of bFGF immunoreactivity. This experiment was done to compare bFGF immunoreactivity in intact females and ovariectomized females at a number of time points after surgery. Although the analysis of GFAP-immunoreactive surface density in Experiment 1 provided clear evidence of changes in astrocytic activity in the VTA, the findings paralleled the changes seen in bFGF expression. It was decided, therefore, for practical reasons to measure only bFGF immunoreactivity in this study because of the large number of brain sections needed to complete such a time course experiment. For this experiment, adult female rats were either ovariectomized (Ovx group) or sham-operated (Intact group) under Metofane anesthesia by bilateral dorsal incisions. Animals were killed 1, 2, 4, 8, and 40 weeks after surgery. With the exception of the animals killed at 40 weeks in which cycles were difficult to detect, all animals were killed on the afternoon of the estrus phase of the estrous cycle of the animals in the Intact group (defined by the presence of cornified cells in the vaginal smear), and their brains were processed for bFGF immunoreactivity. To induce synchrony of the estrous cycle within each Intact group and to prevent any possible effects of long-term isolation within the 40 week groups, we housed together the animals that had undergone the same hormonal manipulation (ovariectomy or sham surgery) and that were going to be killed at the same time point after surgery $(1,2,4,8$, and 40 weeks) during the time between surgery and killing. Daily vaginal smears were taken from all animals. Within each Intact group (1, 2, 4, 8, and 40 weeks) the animals from which the afternoon of estrus could not be identified clearly at the time of perfusion were not used in the study.

First, we analyzed bFGF immunoreactivity within the same brain regions assessed in Experiment 1B (DR, NAcc shell, NAcc core, layer II of the Ent and of the PFC, and layers V and VI of the Oc2) in brains of animals killed 4 weeks after ovariectomy. On the basis of the findings from 4 weeks after ovariectomy, we subsequently investigated levels of bFGF immunoreactivity within the VTA and Ent 1, 2, 8, and 40 weeks after surgery. Levels of bFGF immunoreactivity within the PFC also were examined at these time intervals, with the exception of 8 weeks for which sections were not available.

Experiment 3: Double-labeling study. To examine the nature of the cells expressing bFGF in the regions that were analyzed, we killed two ovariectomized rats given either EB or oil replacement under the same conditions as animals in Experiment 1 at $24 \mathrm{hr}$ after the last EB or oil injection; we processed their brains for bFGF-GFAP and bFGF-TH double-labeling immunohistochemistry.

Experiment 4: Dendritic branching of layer II/III pyramidal cells of the Ent. In a previous study we found increases in the dendritic arbor of pyramidal neurons in parietal cortex several months after ovariectomy of adult females (Stewart and Kolb, 1994). We had argued at that time that these changes might arise in response to mild injury or a reduction of neural input brought about by the sudden and complete loss of estrogens. To examine whether similar changes might be seen after ovariectomy in cortical areas found to increase the expression of bFGF in the present experiment and to determine whether these changes could be prevented by estrogen replacement, we studied cells in the Ent of rats ovariectomized at 80-90 d of age and treated immediately with EB $(n=6)$ or OIL $(n=5)(10 \mu \mathrm{g}$ every other day for 4 weeks or $0.1 \mathrm{ml}$ peanut oil only). These female Wistar rats were part of another ongoing study and were born and raised in the laboratory at Concordia University; with the exception of the dose of EB given, they were treated similarly to those in the other experiments.

\section{Statistical analysis}

For GFAP and bFGF, all analyses were done on the raw data, using estimates of GFAP-immunoreactive surface density and the number of GFAP- and bFGF-immunoreactive cells per square millimeter. For Experiment 1, comparisons were made between the EB-treated group and oil-treated group within a single region. Likewise, in Experiment 2, because the number of bFGF-immunoreactive cells differed considerably as a function of time after surgery, differences between Intact and Ovx groups were tested within a region in animals that were killed at the same time after surgery. The data were analyzed by using Student's $t$ tests for independent samples. All data in the figures are presented as a percentage of the mean of the EB group in a particular region in Experiment 1 and as a percentage of the mean of the Intact group killed at the same time in a particular region in Experiment 2. For the Golgi study the data for dendritic branches were analyzed by ANOVA for group $\times$ branch order for apical and basilar dendrites separately; the data for dendritic length also were analyzed by ANOVA. Similarly, the data of numbers of spines were analyzed by ANOVA for group by spine location.

\section{RESULTS}

\section{Experiment 1A: GFAP-immunoreactive surface density in VTA and DR of ovariectomized animals with EB or oil replacement}

Changes in astrocytic morphology were assessed by using GFAPimmunoreactive surface density in the VTA and DR of adult female rats 4 weeks after ovariectomy with or without estrogen replacement ( $5 \mu \mathrm{g}$ every $4 \mathrm{~d}$ ). As shown in Figure 1, within the VTA the surface density of GFAP-immunoreactive cell bodies and processes was significantly higher $(68 \pm 11 \%)$ in the brains of ovariectomized animals without estrogen replacement. No difference in GFAP-immunoreactive surface density was found in the DR. In agreement with previous findings, no effects of hormonal manipulations on the number of GFAP-immunoreactive astrocytes were observed in either region (Luquin et al., 1993).

\section{Experiment 1B: bFGF immunoreactivity in ovariectomized animals with EB or oil replacement}

Figure 2 shows the mean number of bFGF-immunoreactive cells within several areas of the brain of the ovariectomized animals treated with EB or oil every $4 \mathrm{~d}$ for 4 weeks. It can be seen that the number of bFGF-immunoreactive cells within the VTA ( $86 \pm$ $23 \%)$ and Ent $(203 \pm 67 \%)$ was significantly higher in ovariectomized females without estrogen replacement. No differences were found within the DR, NAcc shell, NAcc core, PFC, or Oc2.

The photomicrographs in Figure 3 provide examples of bFGF immunoreactivity in the Ent of two ovariectomized animals treated with either EB or oil every $4 \mathrm{~d}$ for 4 weeks. A greater number of darkly labeled bFGF-immunoreactive cells can be 


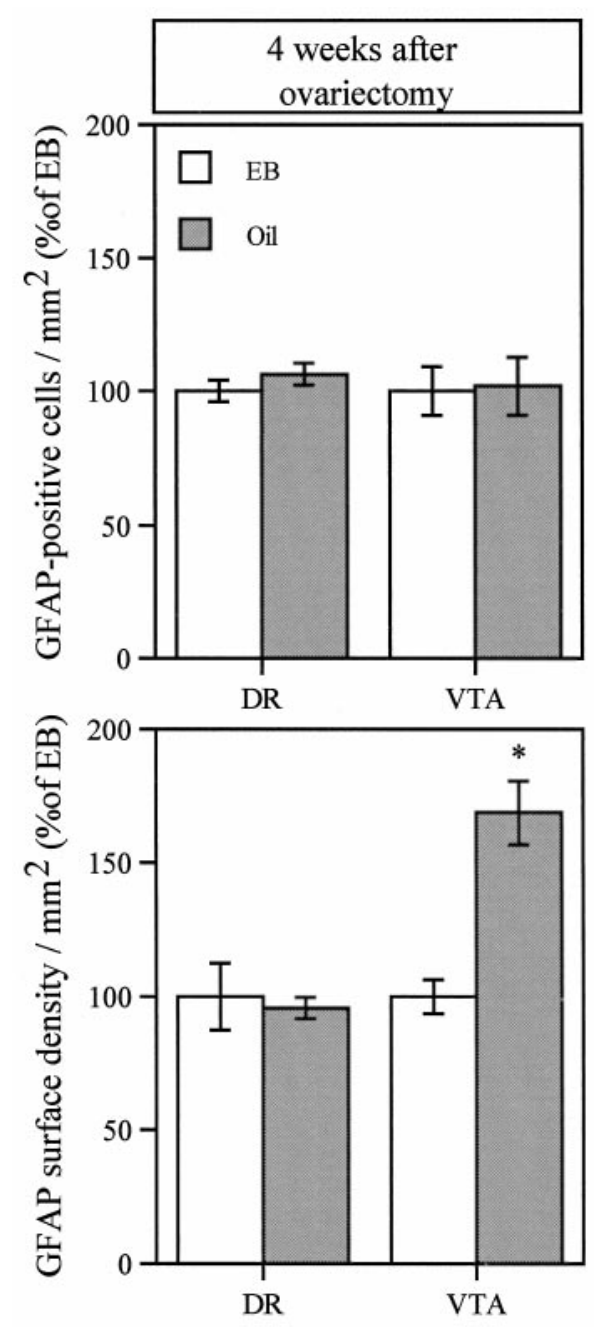

Figure 1. Glial fibrillary acidic protein $(G F A P)$-immunoreactive cells and surface density in dorsal raphe $(D R)$ and ventral tegmental area $(V T A)$. Values are expressed as the mean \pm SEM percentage of the levels in estradiol benzoate $(E B)$-treated animals. All animals were ovariectomized and treated with either EB ( $5 \mu \mathrm{g}$ every $4 \mathrm{~d}$ for 4 weeks; VTA, $n=$ 4 ; DR, $n=4)$ or oil $(0.1 \mathrm{ml}$ of peanut oil every $4 \mathrm{~d}$ for 4 weeks; VTA, $n=$ 3 ; DR, $n=4)$. *Student's $t$ test conducted on the actual counts of the VTA showed a significant difference between EB and oil treatment $[t(5)=$ $5.77 ; p=0.002]$.

seen in layer II of the Ent of ovariectomized animals without estrogen replacement.

\section{Experiment 2: bFGF immunoreactivity in intact versus ovariectomized rats 4 weeks after surgery}

In this experiment, bFGF immunoreactivity was first assessed within the DR, NAcc shell, NAcc core, Ent, PFC, and Oc2 in ovariectomized and intact animals 4 weeks after surgery. As depicted in Figure 4, ovariectomy produced significant increases in the number of bFGF-labeled cells within the VTA $(31 \pm 10 \%)$ and within the Ent $(60 \pm 8 \%)$. Although there was a noticeable increase in bFGF immunoreactivity within the PFC (22 \pm $7 \%$ ) in the Ovx group, this difference did not reach statistical significance.

It should be noted that the percentage of difference in bFGF immunoreactivity between ovariectomized oil-treated rats and EB-treated rats in Experiment 1 was greater than that between ovariectomized and intact animals killed 4 weeks after surgery in

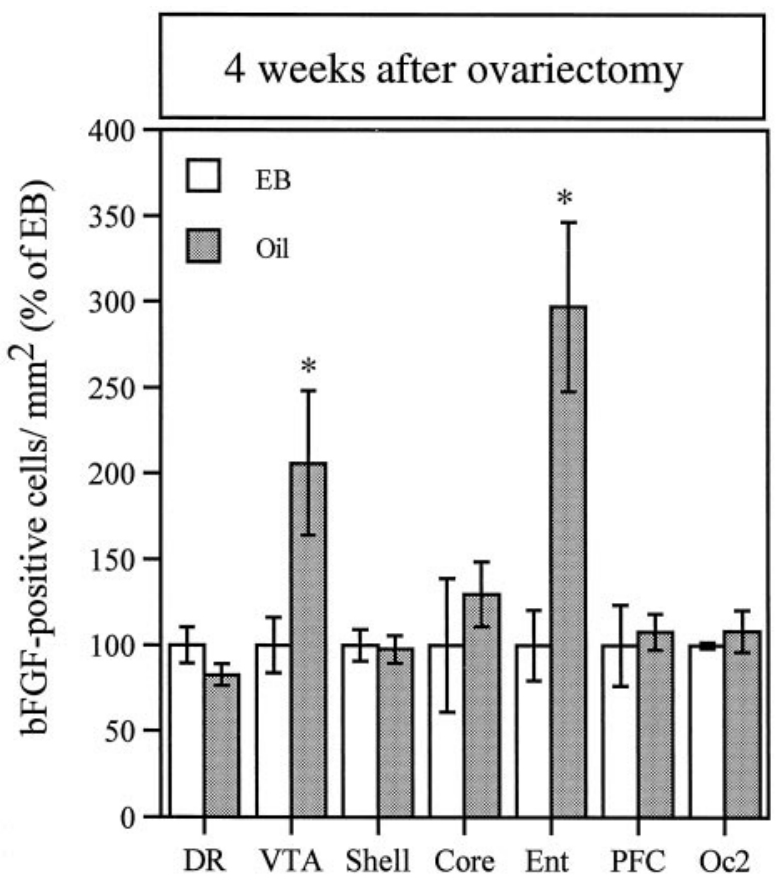

Figure 2. bFGF immunoreactivity in the dorsal raphe $(D R)$, ventral tegmental area (VTA), nucleus accumbens shell (Shell), nucleus accumbens core (Core), entorhinal cortex (Ent), prefrontal cortex $(P F C)$, and occipital cortex area $2(O c 2)$. Values are expressed as the mean \pm SEM percentage of the levels in estradiol benzoate (EB)-treated animals. All animals were ovariectomized and treated with either EB $(5 \mu \mathrm{g}$ every $4 \mathrm{~d}$ for 4 weeks; midbrain regions, $n=4$; forebrain regions, $n=3)$ or oil ( 0.1 $\mathrm{ml}$ every $4 \mathrm{~d}$ for 4 weeks; midbrain regions, $n=4$; forebrain regions, $n=$ $3)$. *Student's $t$ test conducted on the actual counts of the VTA and Ent showed a significant difference between EB and oil treatment [VTA, $t$ $(6)=3.06, p=0.02$; Ent, $t(6)=2.78, p=0.03]$.

Experiment 2. Several factors may have accounted for this difference, including the dose of estradiol used in Experiment 1 and/or the absence of progesterone. Future studies will be needed to examine these issues.

\section{Time course of the changes in bFGF immunoreactivity}

We next assessed the time course of the changes in the number of bFGF-immunoreactive cells within those areas showing increases 4 weeks after ovariectomy: the VTA, Ent, and PFC. As shown in Figure 5, although not all of the changes that were observed were statistically significant, there was a gradual increase in bFGF immunoreactivity within the VTA of ovariectomized rats. These changes appeared to peak between 4 and 8 weeks and to return to levels similar to those observed in intact animals by 40 weeks. Similarly, within the Ent the number of cells expressing bFGF immunoreactivity showed a small increase 2 weeks after ovariectomy. At 4 weeks the increase was statistically significant and then decreased at 8 weeks and returned to levels similar to those in intact animals after 40 weeks. The changes in expression of bFGF immunoreactivity within the PFC were minimal, as shown in Figure 5. No differences were observed until 4 weeks after ovariectomy $(.10>p<0.05)$. At 40 weeks after ovariectomy the number of bFGF-immunoreactive cells returned to levels seen in intact animals. It is interesting, however, that just as was seen in other areas at 40 weeks, there was a small but nonsignificant decrease $(18 \pm 4 \%)$ in bFGF immunoreactivity in Ovx groups. 

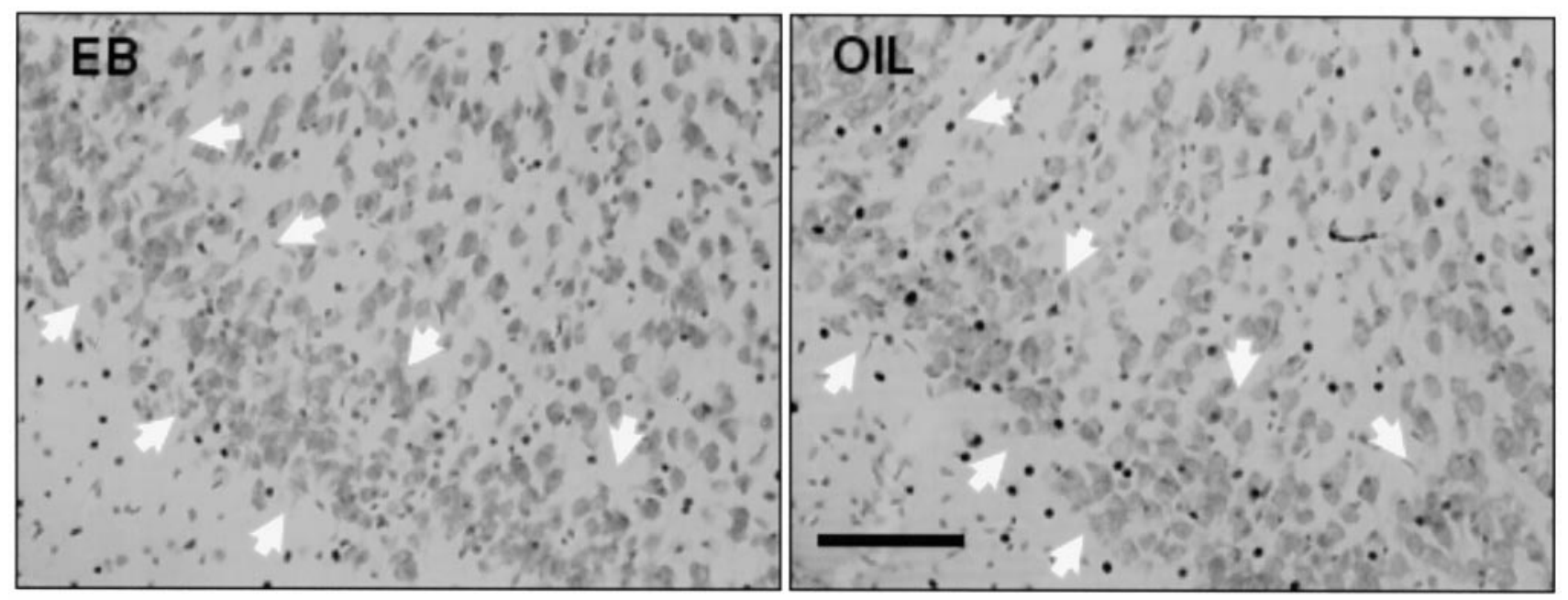

Figure 3. Digitized images showing darkly labeled bFGF-immunoreactive cells (black dots) in tissue lightly counterstained with cresyl violet (lightly stained cells in the background). Images were taken from the entorhinal cortex of representative animals that were ovariectomized and treated with either $5 \mu \mathrm{g}$ of estradiol $(E B)$ or $0.1 \mathrm{ml}$ of peanut oil $(O I L)$ every $4 \mathrm{~d}$ for 4 weeks. The area delimited by the white arrows corresponds to layer II, the region from which the number of bFGF-immunoreactive cells was assessed. Scale bar, $100 \mu \mathrm{m}$.

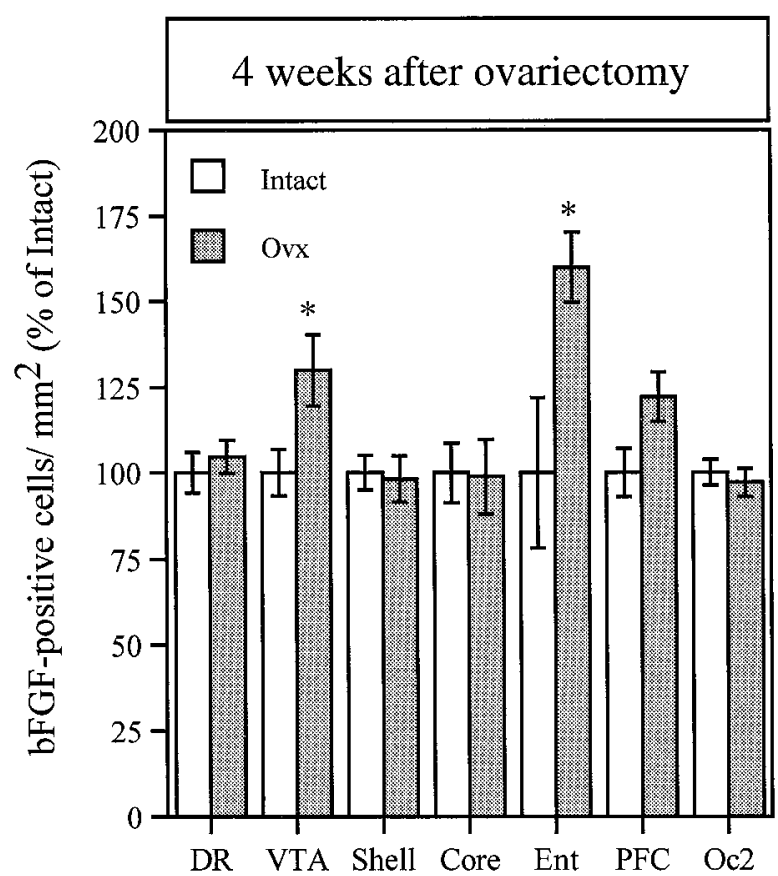

Figure 4. bFGF immunoreactivity in the dorsal raphe $(D R)$, ventral tegmental area $(V T A)$, nucleus accumbens shell (Shell), nucleus accumbens core (Core), entorhinal cortex (Ent), prefrontal cortex $(P F C)$, and occipital cortex area $2(O c 2)$. Values are expressed as the mean \pm SEM percentage of the levels in intact animals. Intact animals were killed in the afternoon of the estrus phase of their estrous cycle, 4 weeks after sham surgery (all regions, $n=4$, except Oc2, $n=3$ ). Ovariectomized animals were killed 4 weeks after surgery (all regions, $n=4$, except PFC, $n=3$ ). *Student's $t$ test conducted on the actual counts [VTA, $t(6)=2.42, p=$ 0.05 ; Ent, $t(6)=2.48, p=0.04$; PFC, $t(5)=2.16 ; p=0.08]$.

\section{Localization of the expression of bFGF immunoreactivity}

Brain sections from two ovariectomized animals that received either oil or EB $(5 \mu \mathrm{g})$ replacement every $4 \mathrm{~d}$ for 4 weeks were double-labeled with bFGF-GFAP and bFGF-TH. In agreement with our previous study (Flores et al., 1998), these studies re- vealed that in all areas that were examined bFGF-positive cells were also GFAP-positive and that in the VTA the dopaminergic neurons did not express bFGF. The photomicrographs shown in Figure 6 were taken from the VTA region of the ovariectomized animal without EB treatment. Figure $6 A$ shows bFGF-GFAP double labeling and Figure $6 B$ shows bFGF-TH double labeling. bFGF immunoreactivity was seen only in astrocytes, never in TH-positive cells. As can be seen, however, not all GFAP-positive astrocytes expressed bFGF. Similar findings were observed in the brain of the EB-treated rat (data not shown).

\section{Morphology of cells in entorhinal cortex}

Figure 7 shows the number of branches on the apical dendrites of layer II/III pyramidal cells in the entorhinal cortex 4 weeks after ovariectomy. It can be seen that, in general, there were more branches on the cells from ovariectomized animals treated with oil than there were on the cells from those treated with estrogen. This effect was statistically significant only for the first and second order branches ( $p$ values $<0.05$ ). In the case of the basilar branches, although the mean numbers were consistently higher in cells from oil-treated animals, there were no significant differences between OIL- and EB-treated animals. The Sholl analysis revealed no significant differences between groups in dendritic length. No significant differences were found in the numbers of spines in any of the regions that were counted.

\section{DISCUSSION}

\section{Effects in cell body regions}

We explored the effects of ovariectomy on astrocytic activity, as reflected by the expression of GFAP and bFGF, in cell body regions of dopaminergic neurons in the VTA and serotonergic neurons in the DR at 4 weeks after surgery. In Experiment 1 it was found that in the VTA the surface density of GFAP-positive astrocytes was greater in ovariectomized animals than in animals given estrogen replacement (5 $\mu \mathrm{g}$ of EB every $4 \mathrm{~d}$ for 4 weeks). In both Experiments 1 and 2 bFGF expression in the VTA was greater in ovariectomized females than in estrogen-replaced or intact groups. There were no differences between groups in either study in the DR. 

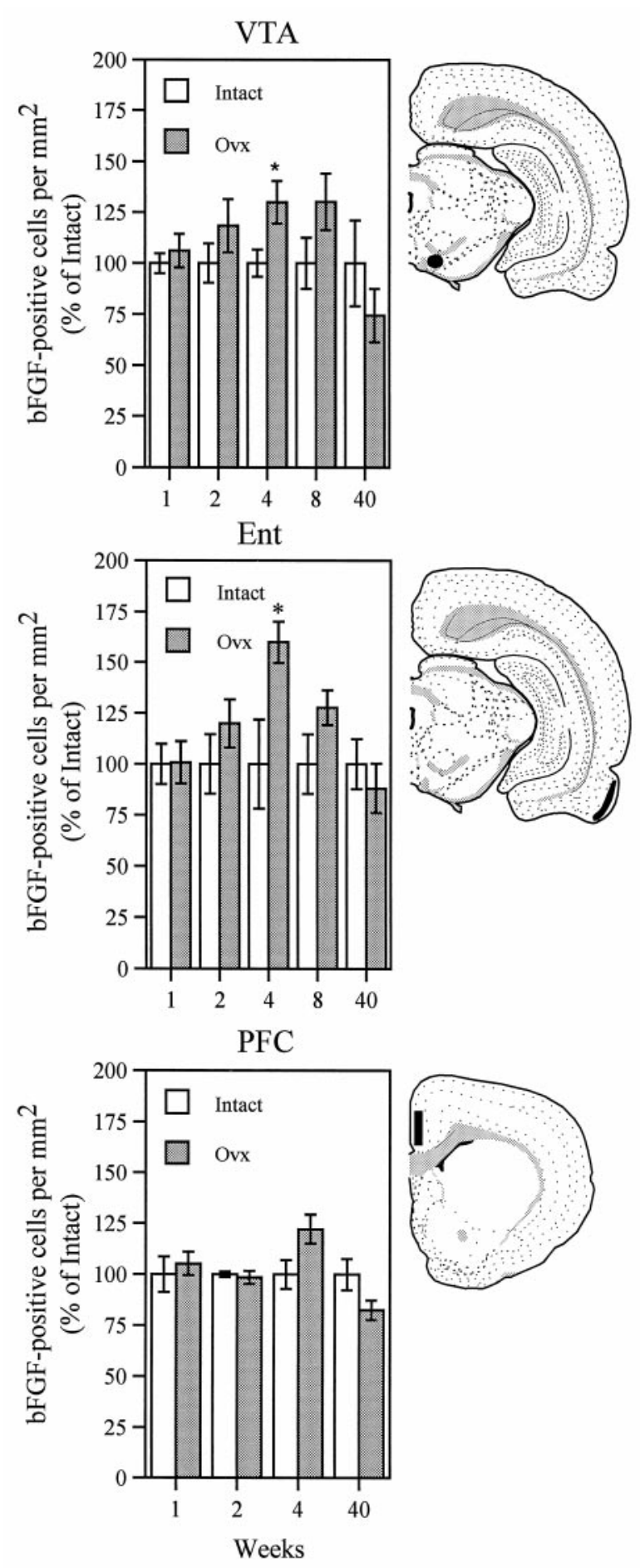

Figure 5. bFGF immunoreactivity in the ventral tegmental area $(V T A)$, entorhinal cortex $(E n t)$, and prefrontal cortex $(P F C)$. Values are expressed as the mean \pm SEM percentage of the levels in intact animals. Intact animals were killed $1,2,4,8$, and 40 weeks after sham surgery on the afternoon of the estrus phase of their estrous cycle $(n=4$, except at 1 week, $n=3$ ). Ovariectomized animals were killed $1,2,4,8$, and 40 weeks after surgery (VTA and Ent, $n=4$, except at 1 week, $n=3$; PFC, $n=3$, except at 2 weeks, $n=4)$. *Student's $t$ tests conducted on the actual counts showed a significant difference between groups 4 weeks after ovariectomy [VTA, 4 weeks, $t(6)=2.42, p=0.05$; Ent, 4 weeks, $t(6)=$ $2.48, p=0.04$; PFC, 4 weeks, $t(5)=2.16, p=0.08]$. The sampling areas from which the number of bFGF-immunoreactive cells was assessed are indicated in black on the adjacent tracing of the coronal plate taken from the Swanson atlas (1992).
Changes in astrocytic bFGF and/or GFAP expression similar to those seen here have been observed in the VTA after toxic insults to dopaminergic neurons and after drug-induced increases in dopaminergic activity (Stromberg et al., 1986; Beitner-Johnson et al., 1993; Chadi et al., 1994; Flores et al., 1998). These changes may be part of a cascade of neuroprotective events initiated by insult. bFGF promotes growth and survival of dopaminergic cells (see Chadi et al., 1993; Bouvier and Mytilineou, 1995) and upregulates GFAP surface density (Gómez-Pinilla et al., 1995); furthermore, the effects of bFGF on dopaminergic function appear to be mediated by astrocytes (Engele and Bohn, 1991; Hou et al., 1997).

How estrogen loss induces injury-like reactions in particular brain regions is unknown. Estrogens have anti-oxidative effects that are independent of the activation of estrogen receptors (Behl et al., 1997; Green et al., 1998; Sawada et al., 1998). Interestingly, oxidative events are associated with lesions of the dopaminergic system (Cohen and Heikkila, 1974), and the protective actions of bFGF on dopaminergic cells are mediated, at least in part, via anti-oxidative effects (Hou et al., 1997). Thus, one interpretation of the present findings is that a sudden loss of estrogen serves as a minor insult to dopaminergic neurons in the VTA, leading to the recruitment of a series of neuroprotective events. In support of this idea is the evidence that, in the absence of estrogens, neurons are more vulnerable to the toxic effects of a variety of insults (Bishop and Simpkins, 1994; Green et al., 1997), including those to the midbrain dopaminergic system (Dluzen et al., 1996; Dluzen, 1997).

Alternatively, the observed changes might well be mediated via effects at estrogen receptors. The VTA contains, however, only a few cells that express the classic nuclear estrogen receptor- $\alpha$. These cells are found within VTA subregions that were examined in the present study but are nondopaminergic. In fact, the morphology of some of the estrogen receptor- $\alpha$-immunoreactive cells within the VTA suggests that they are glia (Kritzer, 1997), and astrocytes are known to express estrogen receptors- $\alpha$ (JungTestas et al., 1991; Santagati et al., 1994). Another possibility is that the effects are mediated by the estrogen receptor- $\beta$, the mRNA for which is densely expressed in the VTA (Shughrue et al., 1997), or by effects at estrogen membrane sites (Ramirez and Zheng, 1996).

It contrast to the VTA, no effects were found in the DR in either experiment. This lack of effects was somewhat surprising considering the known influence of estrogens on serotonergic function (Fink and Sumner, 1996; Fink et al., 1996; PecinsThompson et al., 1996, 1998; Pecins-Thompson and Bethea, 1999) and the presence of estrogen receptor- $\alpha$ protein in this area (Alves et al., 1998). The disparity between the observations in the VTA and DR supports the idea that the effects of ovarian hormones on astrocytic function are restricted to specific brain regions (Luquin et al., 1993).

\section{Effects in cortical regions}

A major finding of the present study is that 4 weeks after surgery bFGF expression was higher in the entorhinal cortex of ovariectomized animals without estrogen. bFGF immunoreactivity was assessed in layer II of the rostral entorhinal cortex, a region that receives substantial innervation from dopaminergic cells of the VTA (Fallon and Loughlin, 1987; Akil and Lewis, 1993, 1994). Cells within these layers of the entorhinal cortex also receive a major input from cholinergic cells of the basal forebrain (Luiten et al., 1987) that also are known to be sensitive to changes in 

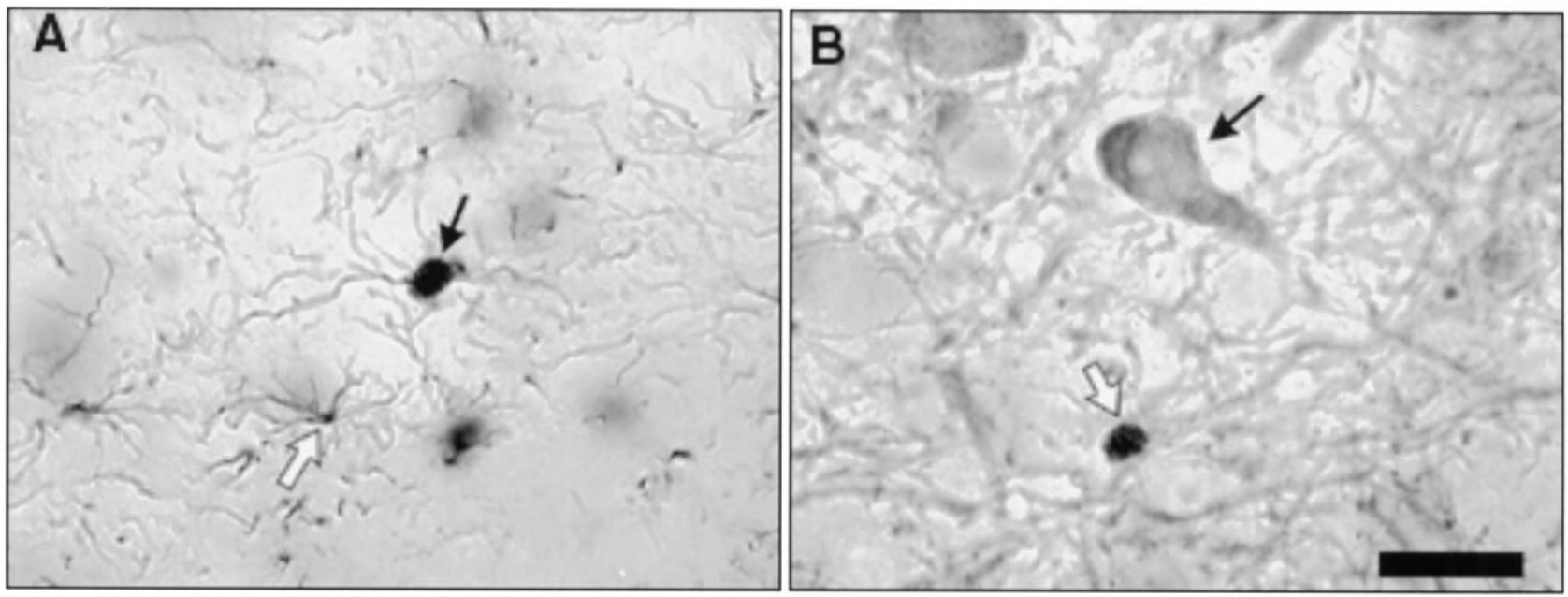

Figure 6. Digitized images from the ventral tegmental area of an ovariectomized animal given estradiol benzoate (EB) replacement (5 $\mu \mathrm{g}$ every $4 \mathrm{~d}$ ) and killed 4 weeks after surgery. $A$, Section labeled with both GFAP and bFGF. The black arrow points to an astrocyte labeled with both bFGF and GFAP. The white arrow points to an astrocyte that was not bFGF-immunoreactive. $B$, Section labeled with both tyrosine hydroxylase (TH) and bFGF. bFGF immunoreactivity (indicated by the white arrow) was not found within TH-positive cells (indicated by the black arrow). Oil immersion. Scale bar, $20 \mu \mathrm{m}$.

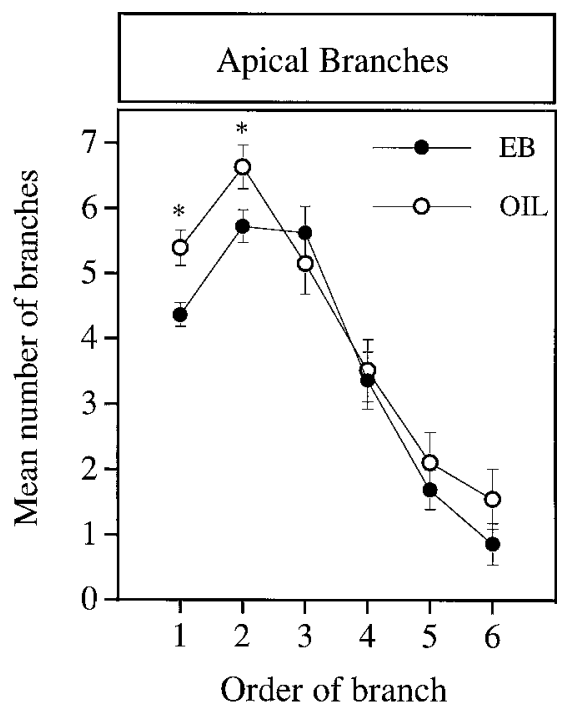

Figure 7. Mean \pm SEM number of apical dendritic branches as a function of order in layer II/III entorhinal cortex in adult ovariectomized females given EB replacement ( $10 \mu \mathrm{g}$ every $2 \mathrm{~d}$ for 4 weeks) or OIL ( 0.1 $\mathrm{ml}$ every $2 \mathrm{~d}$ for 4 weeks). *Significantly different from $\mathrm{EB}(p<0.05)$.

estrogen levels (Luine, 1985; Toran-Allerand et al., 1992; McMillan et al., 1996; Gibbs and Aggarwal, 1998). Interestingly, cells of layer II are among the first to undergo neurofibrillary changes in Alzheimer's disease (Braak and Braak, 1992).

Recently, it has been found that bFGF protects entorhinal cortex layer II neurons from injury induced by lesions of the perforant path carrying fibers to and from the hippocampus (Cummings et al., 1992; Peterson et al., 1996). In addition, bFGF mRNA expression is upregulated in entorhinal cortex after electroconvulsive shock (Follesa et al., 1994) and seizures (Riva et al., 1992). Thus, the increased expression of bFGF in entorhinal cortex found in the present study is suggestive of an injury-like response to ovariectomy that may or may not be related to the effects observed within the VTA. Estrogen receptor binding is seen in the entorhinal cortex (Pfaff and Keiner, 1973; Loy et al.,
1988), as are mRNAs for both estrogen receptor- $\alpha$ and $-\beta$ (see Pelletier et al., 1988; Simerly et al., 1990; Shughrue et al., 1997). In light of these findings it will be important to determine whether lesions of the dopaminergic neurons of the VTA alter the expression of bFGF in the entorhinal cortex.

We also found, 4 weeks after ovariectomy, a small but nonsignificant increase in bFGF expression in supragenual layer II of the medial PFC, a region innervated by midbrain dopaminergic cells (Fallon and Loughlin, 1987). There was, however, no difference between ovariectomized animals and animals given the 4 week estrogen treatment within this region. This lack of effect of estrogen on bFGF expression in this region might have resulted from the fact that estrogen, but not progesterone, was replaced (see, for example, Kritzer and Kohama, 1998). Again, these effects of ovariectomy may be mediated directly, possibly via estrogen receptor- $\beta$ (Shughrue et al., 1997). However, the facts that PFC receives VTA dopaminergic projections (Fallon and Loughlin, 1987) and that ovariectomy reduces the density of TH-immunoreactive fibers in PFC (Kritzer and Kohama, 1998) suggest that changes in bFGF expression could be related to changes in dopaminergic function, although the noradrenergic system cannot be ruled out. In addition, as discussed in relation to the entorhinal cortex, projections from the basal forebrain also could be involved. No effects of ovariectomy or estrogen replacement were seen in the occipital cortex, suggesting that the changes in bFGF that were seen in the present study are specific to particular cortical areas.

Finally, no differences in bFGF expression were found in the nucleus accumbens in either study at 4 weeks after surgery. The lack of effect of ovariectomy on bFGF expression in this dopaminergic terminal region parallels what is seen after repeated injections of amphetamine (Flores et al., 1998) or after 6-hydroxydopamine lesions (Chadi et al., 1994) when there is sustained upregulation of bFGF in cell body regions, but not in nucleus accumbens. The fact that changes were seen in terminal regions in cortex and not in the nucleus accumbens may reflect differences in characteristics of the midbrain dopamine cells that project to each region (Bunney and Chiodo, 1984; Domesick, 
1988); alternatively, it may reflect locally mediated effects in particular cortical areas or effects brought about by interactions between systems projecting to these areas.

\section{Time course of changes in bFGF immunoreactivity}

In the VTA and entorhinal cortex the changes in bFGF expression induced by ovariectomy developed gradually, increasing at 2 weeks and peaking by 4 weeks. In the medial PFC changes did not appear before 4 weeks. These findings suggest that the reaction to ovariectomy is delayed and prolonged. The fact that the effects of ovariectomy were not evident after 40 weeks may indicate that adjustment to the changes in circulating hormones is complete, bFGF is self-regulating, or the astrocytic response is spent.

\section{Pyramidal cell morphology in entorhinal cortex}

The increase in numbers of apical dendrites of layer II/III pyramidal cells in entorhinal cortex found 4 weeks after ovariectomy in animals without estrogen replacement in the present study, although considerably smaller, parallels the finding of Stewart and Kolb (1994) in parietal cortex when animals were studied 4 months after ovariectomy and compared with intact animals. At the time of the latter study, we suggested that it was likely that the increase in dendritic arbor was mediated indirectly, possibly in response to impaired functioning of cells projecting to the area or locally via effects on astrocytes. Thus, although correlational, the present findings provide additional support for this idea. The effects seen in the entorhinal cortex in these studies are particularly provocative in view of the well documented vulnerability of cells of the entorhinal cortex after injury and in aging. It will now be important to determine whether there is an interaction among the age of the animal at ovariectomy, the length of the period without estrogenic hormones, and the magnitude of the observed changes in this region of the brain.

\section{REFERENCES}

Akil M, Lewis DA (1993) The dopaminergic innervation of monkey entorhinal cortex. Cereb Cortex 3:533-550.

Akil M, Lewis DA (1994) The distribution of tyrosine hydroxylaseimmunoreactive fibers in the human entorhinal cortex. Neuroscience 60:857-874.

Alves S, Weiland N, Hayashi S, McEwen B (1998) Immunocytochemical localization of nuclear estrogen receptors and progestin receptors within the rat dorsal raphe nucleus. J Comp Neurol 391:322-334.

Becker JB (1990) Estrogen rapidly potentiates amphetamine-induced striatal dopamine release and rotational behavior during microdialysis. Neurosci Lett 118:169-171.

Behl C, Skutella T, LezoualXh F, Post A, Widmann M, Newton C, Holsboer F (1997) Neuroprotection against oxidative stress by estrogens: structure-activity relationship. Mol Pharmacol 51:535-541.

Beitner-Johnson D, Guitart X, Nestler EJ (1993) Glial fibrillary acidic protein and the mesolimbic dopamine system: regulation by chronic morphine and Lewis-Fischer strain differences in the rat ventral tegmental area. J Neurochem 61:1766-1773.

Bishop J, Simpkins J (1994) Estradiol treatment increases viability of glioma and neuroblastoma cells in vitro. Mol Cell Neurosci 5:303-308.

Bossé R, Di Paolo T (1996) The modulation of brain dopamine and $\mathrm{GABA}_{\mathrm{A}}$ receptors by estradiol: a clue for CNS changes occurring at menopause. Cell Mol Neurobiol 16:199-212.

Bouvier M, Mytilineou C (1995) Basic fibroblast growth factor increases division and delays differentiation of dopamine precursors in vitro. J Neurosci 15:7141-7149.

Braak H, Braak E (1992) The human entorhinal cortex: normal morphology and lamina-specific pathology in various diseases. Neurosci Res 15:6-31.

Bunney BS, Chiodo LA (1984) Mesocortical dopamine systems: further electrophysiological and pharmacological characteristics. In: Monoamine innervation of cerebral cortex (Descarries L, Reader T, Jasper H, eds), pp 263-277. New York: Liss.

Camp DM, Becker JB, Robinson TE (1986) Sex differences in the effects of gonadectomy on amphetamine-induced rotational behavior in rats. Behav Neural Biol 46:491-495.

Castner SA, Xiao L, Becker JB (1993) Sex differences in striatal dopamine: in vivo microdialysis and behavioral studies. Brain Res 610:127-134.

Chadi G, Møller A, Rosén L, Janson A, Agnati L, Goldstein M, Ögren S-O, Pettersson R, Fuxe K (1993) Protective actions of human recombinant basic fibroblast growth factor on MPTP-lesioned nigrostriatal dopamine neurons after intraventricular infusion. Exp Brain Res 97:145-158.

Chadi G, Cao Y, Pettersson RF, Fuxe K (1994) Temporal and spatial increase of astroglial basic fibroblast growth factor synthesis after 6-hydroxydopamine-induced degeneration of the nigrostriatal dopamine neurons. Neuroscience 61:891-910.

Cohen G, Heikkila R (1974) The generation of hydrogen peroxide, superoxide radical, and hydroxyl radical by 6-hydroxydopamine, dialuric acid, and related cytotoxic agents. J Biol Chem 249:2447-2452.

Coleman P, Riesen A (1968) Environmental effects on cortical dendritic fields. I. Rearing in the dark. J Anat 102:363-374.

Cummings B, Yee G, Cotman C (1992) bFGF promotes the survival of entorhinal layer II neurons after perforant path axotomy. Brain Res 591:271-276.

Dluzen D (1997) Estrogen decreases corpus striatal neurotoxicity in response to 6-hydroxydopamine. Brain Res 767:340-344.

Dluzen D, McDermott J, Liu B (1996) Estrogen alters MPTP-induced neurotoxicity in female mice: effects on striatal dopamine concentrations and release. J Neurochem 66:658-666.

Domesick V (1988) Neuroanatomical organization of dopamine neurons in the ventral tegmental area. Ann NY Acad Sci 537:10-26.

Engele J, Bohn MC (1991) The neurotrophic effects of fibroblast growth factors on dopaminergic neurons in vitro are mediated by mesencephalic glia. J Neurosci 11:3070-3078.

Fallon J, Loughlin S (1987) Monoamine innervation of cerebral cortex and a theory of the role of monoamines in cerebral cortex and basal ganglia. In: Cerebral cortex (Jones E, Peters A, eds), pp 41-127. New York: Plenum.

Fallon JH, Moore RY (1978) Catecholamine innervation of the basal forebrain. IV. Topography of the dopamine projection to the basal forebrain and neostriatum. J Comp Neurol 180:545-580.

Fink G, Sumner B (1996) Oestrogen and mental state. Nature 383:306.

Fink G, Sumner B, Rosie R, Grace O, Quinn J (1996) Estrogen control of central neurotransmission: effect on mood, mental state, and memory. Cell Mol Neurobiol 16:325-343.

Flores C, Rodaros D, Stewart J (1998) Long-lasting induction of astrocytic basic fibroblast growth factor by repeated injections of amphetamine: blockade by concurrent treatment with a glutamate antagonist. J Neurosci 18:9547-9555.

Follesa P, Gale K, Mocchetti I (1994) Regional and temporal pattern of expression of nerve growth factor and basic fibroblast growth factor mRNA in rat brain following electroconvulsive shock. Exp Neurol 127:37-44.

Forgie ML, Stewart J (1993) Sex differences in amphetamine-induced locomotor activity in adult rats: role of testosterone exposure in the neonatal period. Pharmacol Biochem Behav 46:637-645.

Forgie ML, Stewart J (1994) Effect of prepubertal ovariectomy on amphetamine-induced locomotor activity in adult female rats. Horm Behav 28:241-260.

García-Segura LM, Chowen JA, Párducz A, Naftolin F (1994) Gonadal hormones as promoters of structural synaptic plasticity: cellular mechanism. Prog Neurobiol 44:279-307.

García-Segura ML, Chowen JA, Naftolin F (1996) Endocrine glia: roles of glial cells in the brain actions of steroid and thyroid hormones and in the regulation of hormone secretion. Front Neuroendocrinol 17:180-211.

Gibb R, Kolb B (1998) A method for vibratome sectioning of Golgi-Cox stained whole rat brain. J Neurosci Methods 79:1-4.

Gibbs RB (1998) Levels of trkA and BDNF mRNA, but not NGF mRNA, fluctuate across the estrous cycle and increase in response to acute hormone replacement. Brain Res 787:259-268.

Gibbs RB, Aggarwal P (1998) Estrogen and basal forebrain cholinergic neurons: implications for brain aging and Alzheimer's disease-related cognitive decline. Horm Behav 34:98-111.

Gómez-Pinilla F, Vu L, Cotman C (1995) Regulation of astrocyte proliferation by FGF-2 and heparan sulfate in vivo. J Neurosci 15:2021-2029. 
Gould E, Woolley CS, Frankfurt M, McEwen BS (1990) Gonadal steroids regulate dendritic spine density in hippocampal pyramidal cells in adulthood. J Neurosci 10:1286-1291.

Green PS, Bishop J, Simpkins JW (1997) $17 \alpha$-Estradiol exerts neuroprotective effects on SK-N-SH cells. J Neurosci 17:511-515.

Green PS, Gridley KE, Simpkins JW (1998) Nuclear estrogen receptorindependent neuroprotection by estratrienes: a novel interaction with glutathione. Neuroscience 84:7-10.

Gregoire A, Kumar R, Everitt B, Henderson A, Studd J (1996) Transdermal oestrogen for treatment of severe postnatal depression. Lancet 347:930-933.

Henderson V (1997) The epidemiology of estrogen replacement therapy and Alzheimer's disease. Neurology 48:S27-S35.

Hou J-GG, Cohen G, Mytilineou C (1997) Basic fibroblast growth factor stimulation of glial cells protects dopamine neurons from 6-hydroxydopamine toxicity: involvement of the glutathione system. J Neurochem 69:76-83.

Hsu S, Raine L, Fanger H (1981) The use of anti-avidin antibody and avidin-biotin-peroxidase complex in immunoperoxidase techniques. Am J Clin Pathol 75:816-821.

Jung-Testas I, Renoir J, Gasc J, Baulieu E (1991) Estrogen-inducible progesterone receptor in primary cultures of rat glial cells. Exp Cell Res 193:12-19.

Kolb B, McLimans J (1986) A process for cryostat sectioning of GolgiCox tissue. Stain Technol 61:379-380.

Kolb B, Stewart J, Sutherland RJ (1997) Recovery of function is associated with increased spine density in cortical pyramidal cells after frontal lesions and/or noradrenaline depletion in neonatal rats. Behav Brain Res 89:61-70.

Kritzer M (1997) Selective colocalization of immunoreactivity for intracellular gonadal hormone receptors and tyrosine hydroxylase in the ventral tegmental area, substantia nigra, and retrorubral fields in the rat. J Comp Neurol 379:247-260.

Kritzer M, Kohama S (1998) Ovarian hormones influence the morphology, distribution, and density of tyrosine hydroxylase-immunoreactive axons in the dorsolateral prefrontal cortex of adult rhesus monkeys. J Comp Neurol 395:1-17.

Lindamer L, Lohr J, Harris M, McAdams L, Jeste D (1999) Genderrelated clinical differences in older patients with schizophrenia. J Clin Psychiatry 60:61-67.

Loy R, Gerlach J, McEwen B (1988) Autoradiographic localization of estradiol-binding neurons in the rat hippocampal formation and entorhinal cortex. Dev Brain Res 39:245-251.

Luine V (1985) Estradiol increases choline acetyltransferase activity in specific basal forebrain nuclei and projection areas of female rats. Exp Neurol 89:484-490.

Luiten PGM, Gaykema RPA, Traber J, Spencer Jr DG (1987) Cortical projection patterns of magnocellular basal nucleus subdivisions as revealed by anterogradely transported phaseolus vulgaris leucoagglutinin. Brain Res 413:229-250.

Luquin S, Naftolin F, García-Segura LM (1993) Natural fluctuation and gonadal hormone regulation of astrocyte immunoreactivity in dentate gyrus. J Neurobiol 24:913-924.

Matsuzaki K, Yoshitake Y, Matuo Y, Sasaki H, Nishikawa K (1989) Monoclonal antibodies against heparin-binding growth factor II/basic fibroblast growth factor that block its biological activity: invalidity of the antibodies for tumor angiogenesis. Proc Natl Acad Sci USA 86:9911-9915.

McMillan P, Singer C, Dorsa D (1996) The effects of ovariectomy and estrogen replacement on trkA and choline acetyltransferase mRNA expression in the basal forebrain of the adult female Sprague Dawley rat. J Neurosci 16:1860-1865.

Murphy D, Cole N, Greenberger V, Segal M (1998a) Estradiol increases dendritic spine density by reducing GABA neurotransmission in hippocampal neurons. J Neurosci 18:2550-2559.

Murphy D, Cole N, Segal M (1998b) Brain-derived neurotrophic factor mediates estradiol-induced dendritic spine formation in hippocampal neurons. Proc Natl Acad Sci USA 95:11412-11417.

Paxinos G, Watson C (1997) The rat brain in stereotaxic coordinates, Ed 3. New York: Academic.

Pecins-Thompson M, Bethea C (1999) Ovarian steroid regulation of serotonin-1A autoreceptor messenger RNA expression in the dorsal raphe of rhesus macaques. Neuroscience 89:267-277.
Pecins-Thompson M, Brown N, Kohama S, Bethea C (1996) Ovarian steroid regulation of tryptophan hydroxylase mRNA expression in rhesus macaques. J Neurosci 16:7021-7029.

Pecins-Thompson M, Brown N, Bethea C (1998) Regulation of serotonin reuptake transporter mRNA expression by ovarian steroids in rhesus macaques. Mol Brain Res 53:120-129.

Pelletier G, Liao N, Follea N, Govindan M (1988) Mapping of estrogen receptor-producing cells in the rat brain by in situ hybridization. Neurosci Lett 94:23-28.

Peterson D, Lucidi-Phillipi C, Murphy D, Ray J, Gage F (1996) Fibroblast growth factor-2 protects entorhinal layer II glutamatergic neurons from axotomy-induced death. J Neurosci 16:886-898.

Pfaff D, Keiner M (1973) Atlas of estradiol-concentrating cells in the central nervous system of the female rat. J Comp Neurol 151:121-158.

Ramirez V, Zheng J (1996) Membrane sex-steroid receptors in the brain. Front Neuroendocrinol 17:402-439.

Riva M, Gale K, Mocchetti I (1992) Basic fibroblast growth factor mRNA increases in specific brain regions following convulsive seizures. Mol Brain Res 15:311-318.

Robinson TE (1988) Stimulant drugs and stress: factors influencing individual differences in the susceptibility to sensitization. In: Sensitization in the nervous system (Kalivas PW, Barnes CD, eds), pp 145-173. Caldwell, NJ: Telford.

Santagati S, Melcangi R, Celotti F, Martini L, Maggi A (1994) Estrogen receptor is expressed in different types of glial cells in culture. J Neurochem 63:2058-2064.

Sawada H, Ibi M, Kihira T, Urushitani M, Akaike A, Shimohana S (1998) Estradiol protects mesencephalic dopaminergic neurons from oxidative stress-induced neural death. J Neurosci Res 54:707-719.

Sherwin B (1997) Estrogen effects on cognition in menopausal women. Neurology 48:S21-S26.

Sholl D (1956) The organization of the cerebral cortex. London: Methuen.

Shughrue P, Lane M, Merchenthaler I (1997) Comparative distribution of estrogen receptor- $\alpha$ and $-\beta$ mRNA in the rat central nervous system. J Comp Neurol 388:507-525.

Simerly R, Chang C, Muramatsu M, Swanson L (1990) Distribution of androgen and estrogen receptor mRNA-containing cells in the rat brain: an in situ hybridization study. J Comp Neurol 294:76-95.

Singh M, Meyer EM, Millard WJ, Simpkins JW (1994) Ovarian steroid deprivation results in a reversible learning impairment and compromised cholinergic function in female Sprague Dawley rats. Brain Res 644:305-312.

Sohrabji F, Miranda RC, Toran-Allerand CD (1995) Identification of a putative estrogen response element in the gene encoding brain-derived neurotrophic factor. Proc Natl Acad Sci USA 92:11110-11114.

Stewart J, Kolb B (1994) Dendritic branching in cortical pyramidal cells in response to ovariectomy in adult female rats: suppression by neonatal exposure to testosterone. Brain Res 654:149-154.

Stewart J, Rodaros D (1999) The effects of gonadal hormones on the development and expression of the stimulant effects of morphine in male and female rats. Behav Brain Res 102:89-98.

Stromberg I, Bjorklund H, Dahl D, Jonsson G, Sundstrom E, Olson L (1986) Astrocyte responses to dopaminergic denervations by 6-hydroxydopamine and 1-methyl-4-phenyl-1,2,3,6-tetrahydropyridine as evidenced by glial fibrillary acidic protein immunohistochemistry. Brain Res Bull 17:225-236.

Swanson L (1992) Brain maps: structure of the rat brain. Amsterdam: Elsevier.

Toran-Allerand CD, Miranda RC, Bentham WDL, Sohrabji F, Brown TJ, Hochberg RB, MacLusky NJ (1992) Estrogen receptors colocalize with low-affinity nerve growth factor receptors in cholinergic neurons of the basal forebrain. Proc Natl Acad Sci USA 89:4668-4672.

Weibel E (1979) Stereological methods, Vol 1, Practical methods for biological morphometry. London: Academic.

Woolley CS, McEwen BS (1994) Estradiol regulates hippocampal dendritic spine density via an $N$-methyl-D-aspartate receptor-dependent mechanism. J Neurosci 14:7680-7687.

Woolley CS, Gould E, Frankfurt M, McEwen BS (1990) Naturally occurring fluctuations in dendritic spine density on adult hippocampal pyramidal neurons. J Neurosci 10:4035-4039.

Zilles K (1985) The cortex of the rat: a stereotaxic atlas. New York: Springer. 